\title{
Composite External Fixators: Design with Subsequent FEM Analysis Optimization
}

Filip Tomanec ${ }^{1,2}$, Sona Rusnakova ${ }^{1}$, Jiri Kohut ${ }^{2}$, Martina Kalova ${ }^{2}$

${ }^{1}$ Faculty of Technology, Thomas Bata University in Zlin. T.G. Masaryka 5555, 76001 Zlin, Czech Republic. E-mail: solvetech@solvetech.cz,rusnakova@utb.cz

${ }^{2}$ Center of Advanced Innovation Technologies - VŠB-Technical University of Ostrava, 17. listopadu 15, 70800 OstravaPoruba, Czech Republic

An application of external fixator is a surgical method for the treatment of large bones fractures. This method has been proposed already a century ago, but despite the extensive development of science and technology, the fixator is often used in the original state of the proposal. [1] Therefore the patient and surgeons are dissatisfied with high weight and poor mobility of fixator during surgery and healing process. [2] Due to this fact it is necessary to apply new 3D technologies into this field of orthopedics and thus improve the current state of this tool. [3] In an account of this information, the 3D model of a new composite external fixator was created. In the research, the composite fixator was analyzed by the finite element method (FEM). Based on the results of FEM and the surgeon's requirements, the composite fixator was further improved and the final results show that the composite fixator proposed by the FEM is able to transfer the applied load from a patient. Therefore the data indicates that the implementation of composite material will further improve patients comfort, the healing process and the precision of surgery. Based on this fact, the mold has already been manufactured and the process of completing the product has started.

Keywords: External fixator, finite element method, composite, surgery.

\section{Introduction}

In the field of composite materials as well as in the field of bone tissue engineering large development can be mentioned $[4,5]$. Also, in the design of external fixators, new materials, technologies, and innovations has been applied [6]. Generally, the external fixator (Fig. 1) is a system of mechanical components used for large bone fractures treatment. The function of this device is to firmly hold a broken bone during all the healing process. Another aim is providing appropriate adjustments of fracture fragments in order to successfully finish the healing process [7].

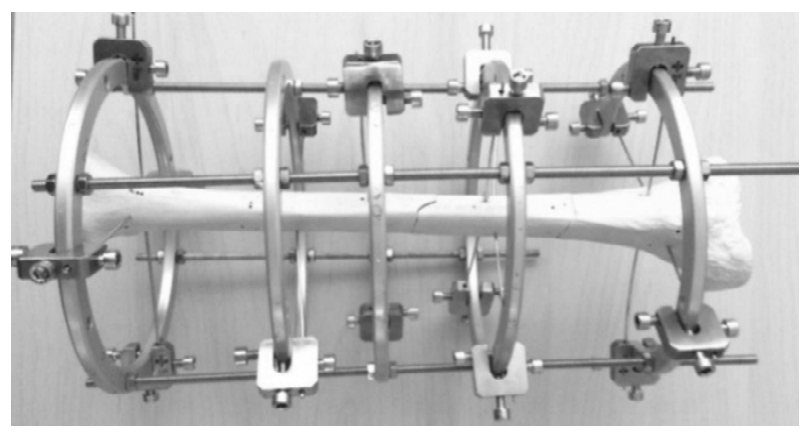

Fig. 1 Ilizarov external fixator of the tibia bone

One of the most commonly used fixators in a healing process of long bones is Ilizarov external fixator (|Fig. 1). This device was established several decades ago [8]. After many years of application, more specific problems with this device has been found. Such as high weight during the healing process, problems with surgery with metal fixator under the X-ray (shown in Fig. 2) and also problems with appearance [9].

In accordance with these problems, design and material changes are necessary. In case of material choice, we can see that the metal material of fixator can be in several components replaced by composite material as shown in previous research $[10,11]$.

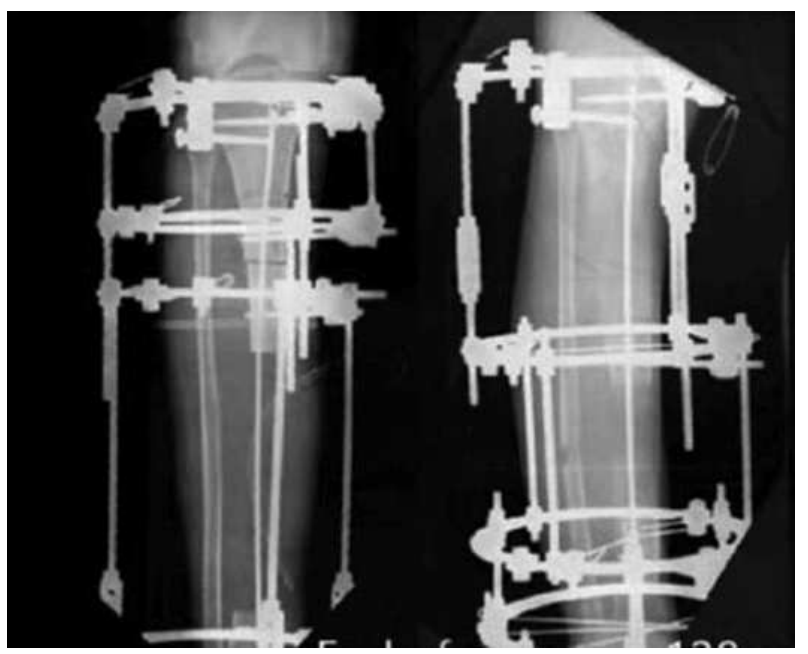

Fig. $2 X$-ray of Ilizarov external fixator after the surgery [12]

Thus, the aim of this project is to finish the design of an external fixator with the application of carbon fiber and epoxy resin composite. The importance of utilization composites materials is the high stiffness at the same time with high strength and low density of this material. To improve the design of final composite fixator, individual versions of the product are analyzed by finite element method (FEM).

\section{Methods and materials}

\section{Design and FEM analysis of external fixator}

In this research, an innovative external fixator for healing fractures of long bones was created (Fig. 3). During the design process, the shape and dimensions were applied from former metal fixator. These dimensions are 
tested and approved. According to the knowledge about the fixator deficiencies, the material of supporting rings has been changed. As a construction material, the sort of composite materials DT806 was selected. Another improvement was a new design of clamping components and replacement of the threaded rod for the composite rod. These improvements of connecting components further help with the simplification of surgery and adjustments during the whole healing process.

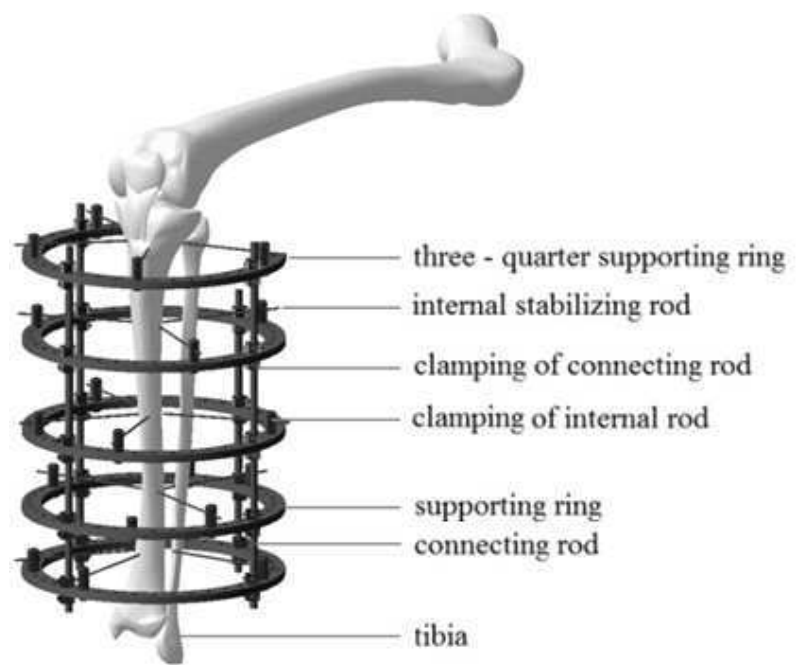

Fig. 3 An external fixator of tibia - version 1

In another step, this new design was evaluated by the FEM analysis (shown in Fig. 4). As can be seen in the Tab. 1, the material constants required for analysis were specified, appropriate load representing the patient weight $(1300 \mathrm{~N})$ was applied and the pushing the foot on the land was replaced by the fixation bond at the bottom part of the fixator. The analysis was calculated, and the results can be seen in Fig. 4.

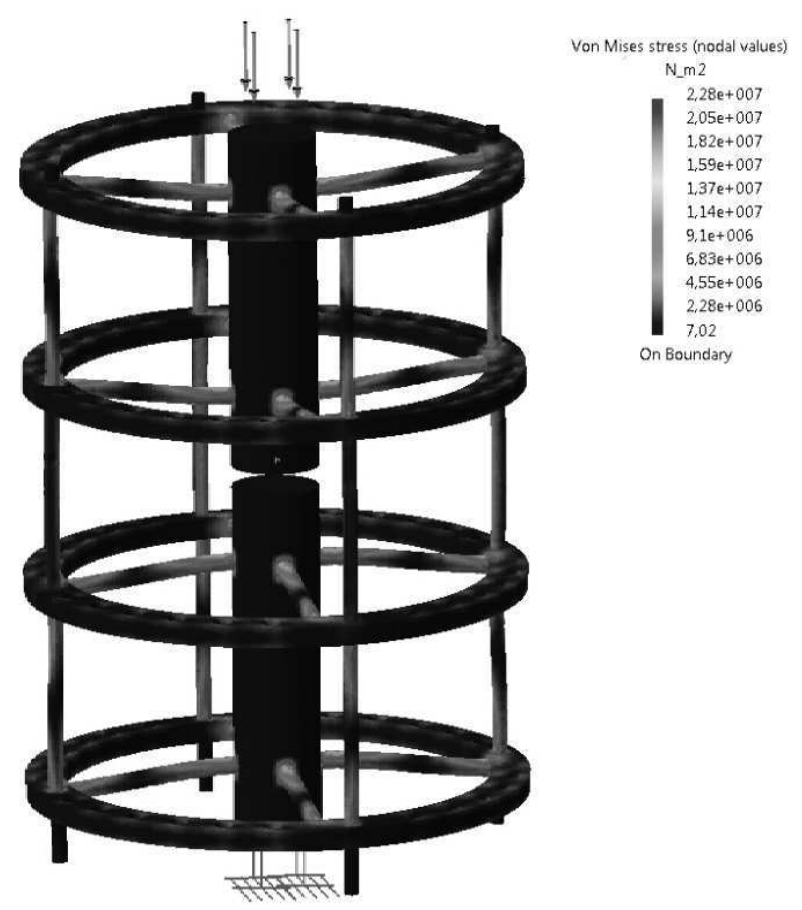

Fig. 4 FEM analysis of external fixator - version 1
According to another evaluation of the fixator design with a surgeon, the requirement to use the fixator over the entire $360^{\circ}$ range at any angle was raised. In the $1 \mathrm{st}$ version of the fixator, the possibility to use all the range was limited by the distance between the individual hole. Regarding this, the design of fixator was improved (Fig. 5.). Most importantly, the holes in supporting rings were replaced by the grooves. This change provided the possibility to use the full range of fixator. Thus, also the diameter of fixator increased.

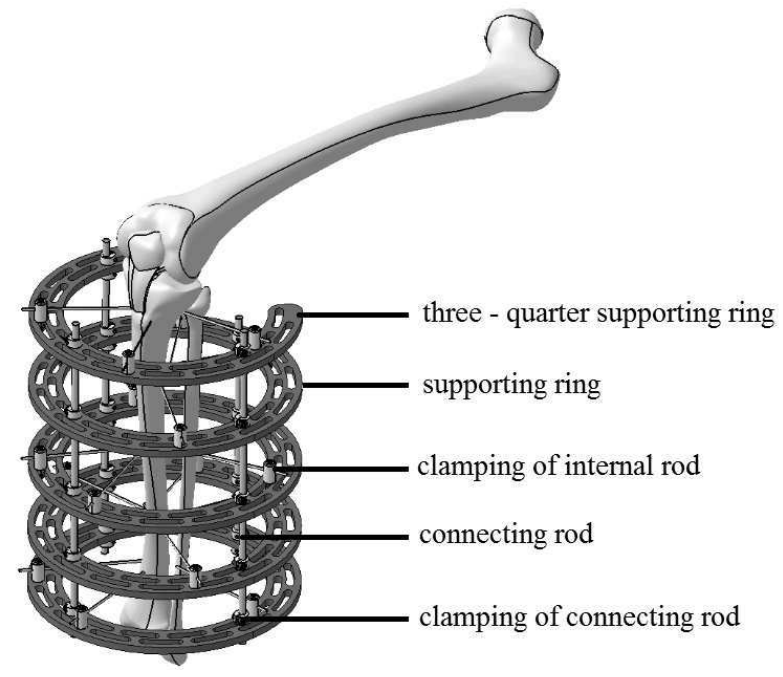

Fig. 5 An external fixator of the tibia with grooves version 2

Tab. 1 Structural properties of carbon composite

\begin{tabular}{|l|l|}
\hline $\begin{array}{l}\text { Structural properties of carbon } \\
\text { composite }\end{array}$ & $\begin{array}{l}\text { Composite fix- } \\
\text { ator }\end{array}$ \\
\hline Young Modulus $(\mathrm{GPa})$ & 30 \\
\hline Poisson Ratio $(-)$ & 0.3 \\
\hline Density $\left(\mathrm{kg} / \mathrm{m}^{3}\right)$ & 2200 \\
\hline
\end{tabular}

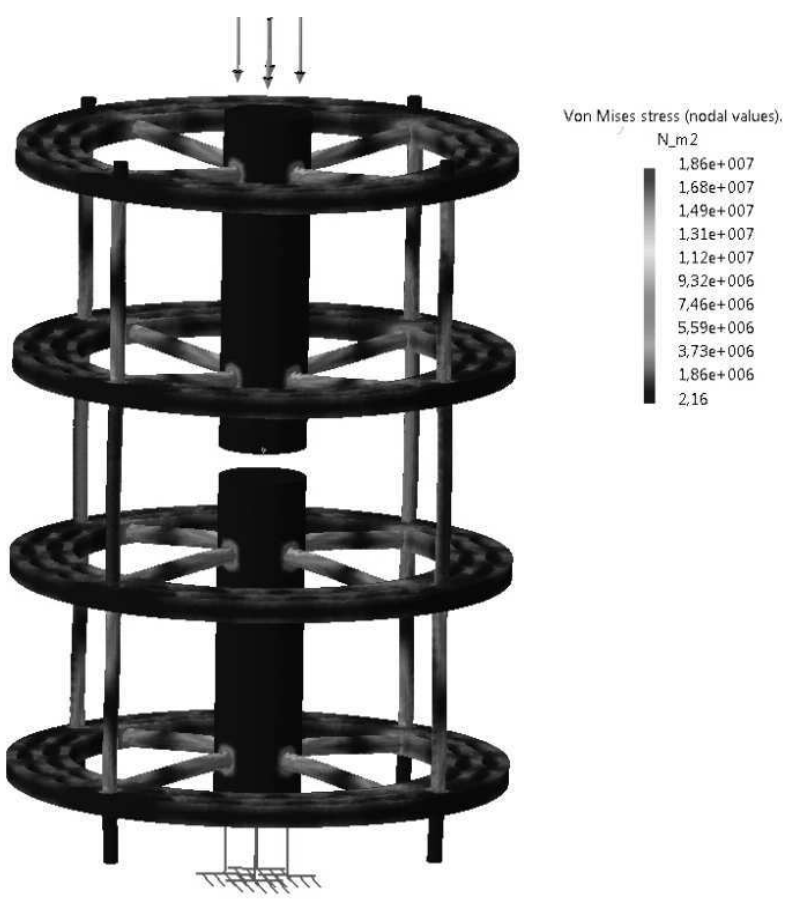

Fig. 6 FEM analysis of external fixator - version 2 
After the completion of a new model, the FEM analysis was applied. In this case, the constraints, forces and material parameters remained unchanged. The rod in the center of fixator represents the simplified model of the broken bone. The results of this analysis can be seen in the picture below (Fig. 6). These results are described in the result section.

The design was modified, FEM analysis applied, and this second version was through roughly evaluated by the surgeon. The changes made are satisfactory, however, there were other possibilities of design modification in order to improve an appearance of the final product. The grooves were created in different length, the composite rings are lightened, and the final shape of every ring is smoother and gradual as can be seen in Fig. 7. For reduction of a complexity of this product and improvement applicability of external fixator, the clamping components are simplified as well.

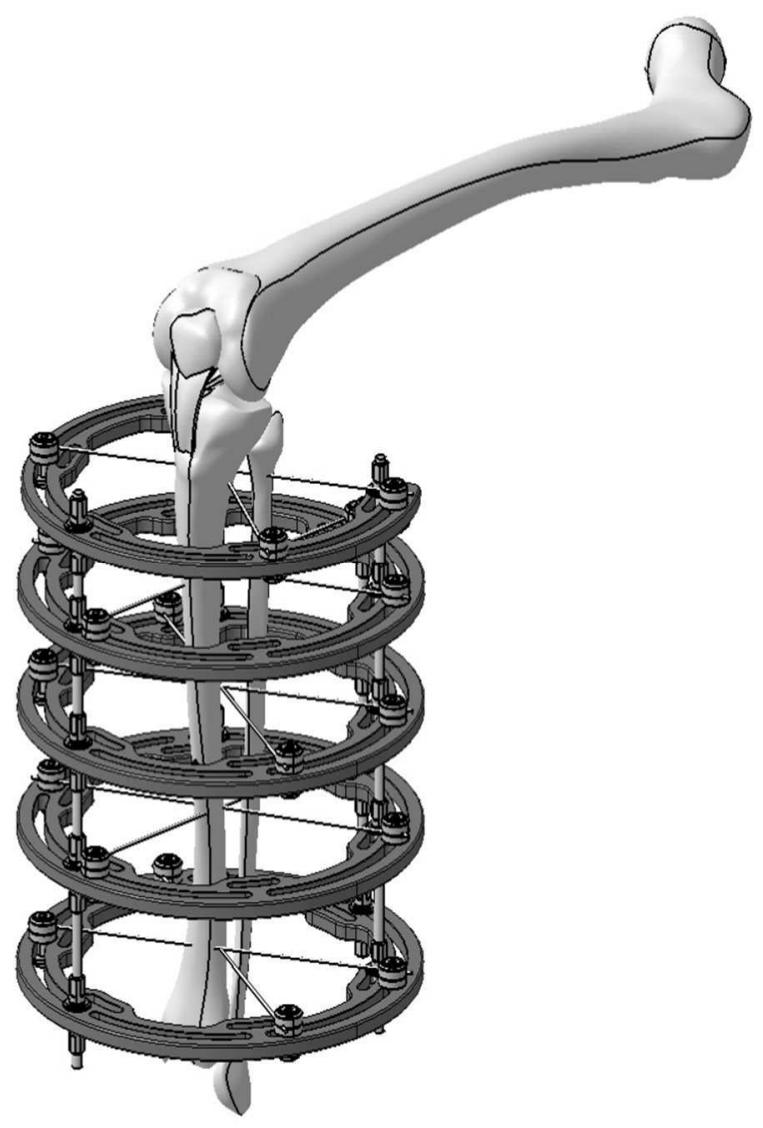

Fig. 7 An external fixator of the tibia with improved grooves - version 3

Final design as previous versions have been evaluated by the same method as the previous modifications and the results of this FEM analysis can be seen in a Fig. 8 .

One of the important requirements for the fixators is the compliance of the maximum value of displacement by $2 \mathrm{~mm}$. In order to finish the design of external fixator, it is important to evaluate if the value of displacement is lower than this maximum value of deformation. As can be seen in Fig. 9, improved fixator loaded by $1300 \mathrm{~N}$ reached displacement $0.55 \mathrm{~mm}$.

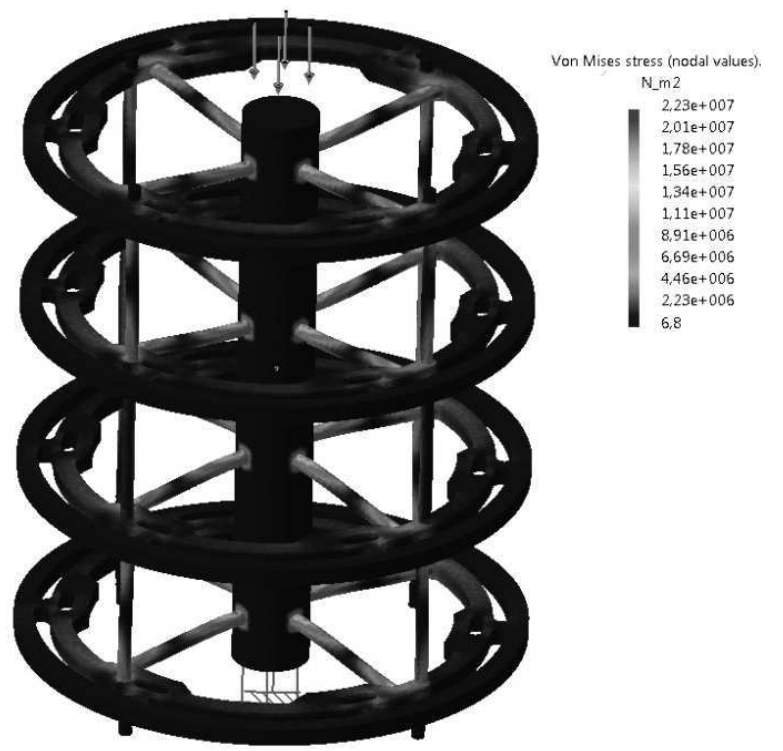

Fig. 8 FEM analysis of external fixator with improved grooves - version 3

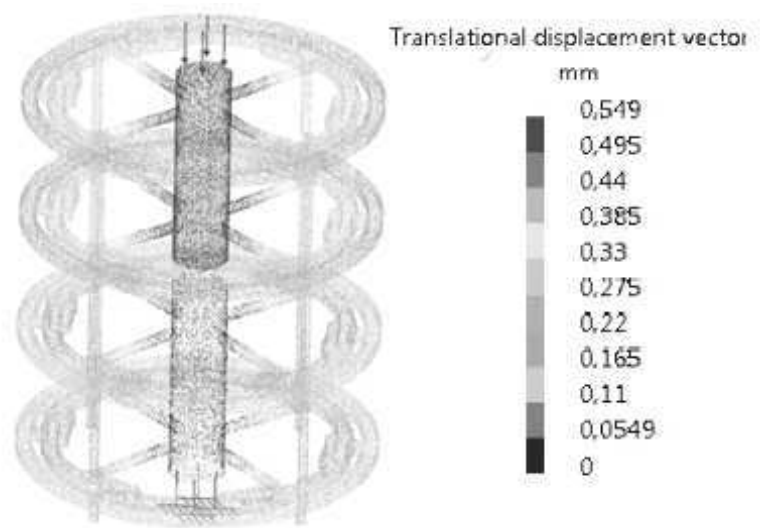

Fig. 9 FEM analysis of external fixator with improved grooves - version 3 - displacement

\section{Results and Discussion}

\section{FEM analysis}

The results of the finite element method analysis of the individual version of the external fixator are united in Tab. 2. The lowest Von Mises stress (18.6 MPa) is calculated in version 2 , where the grooves into the design were applied and the external diameter of the fixator has increased. If we focus on the 1 st version, we can see that the Von Mises stress reached the highest value $(28 \mathrm{MPa})$ and together with the system of holes that do not allow the fixator use at any angle it is the least appropriate option. If the third version is compared, the results of FEM analysis are not as good as results of 2 nd version. However, when the advantages as improved appearance, declined weight are included, then this last version of the composite ring is the most appropriate solution.

In order to verify a quality of the design, the displacement test has been applied. As mentioned in Tab. 2. All the versions of external fixator reach the maximum displacement below the predetermined limit. 
Tab. 2 The comparison of different types of an external fixator

\begin{tabular}{|l|l|l|l|}
\hline Version of fixator & $\begin{array}{l}\text { Maximum Von Misses } \\
\text { stress [MPa] }\end{array}$ & Weight & Displacement \\
\hline Version 1 & 28 & 690 & 0.95 \\
\hline Version 2 & 18.6 & 870 & 0.34 \\
\hline Version 3 & 22.3 & 810 & 0.55 \\
\hline
\end{tabular}

\section{Conclusion}

When it is necessary to solve the problems as high weight, visibility of fixator under the X-ray during the surgery and appearance of this product, the significant changes in material, design, and mounting of external fixator has been done.

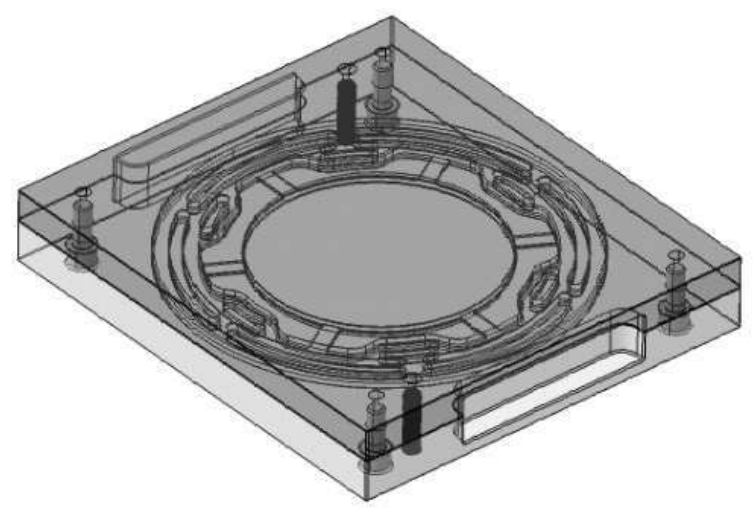

Fig. 10 Design of the mold for the composite ring

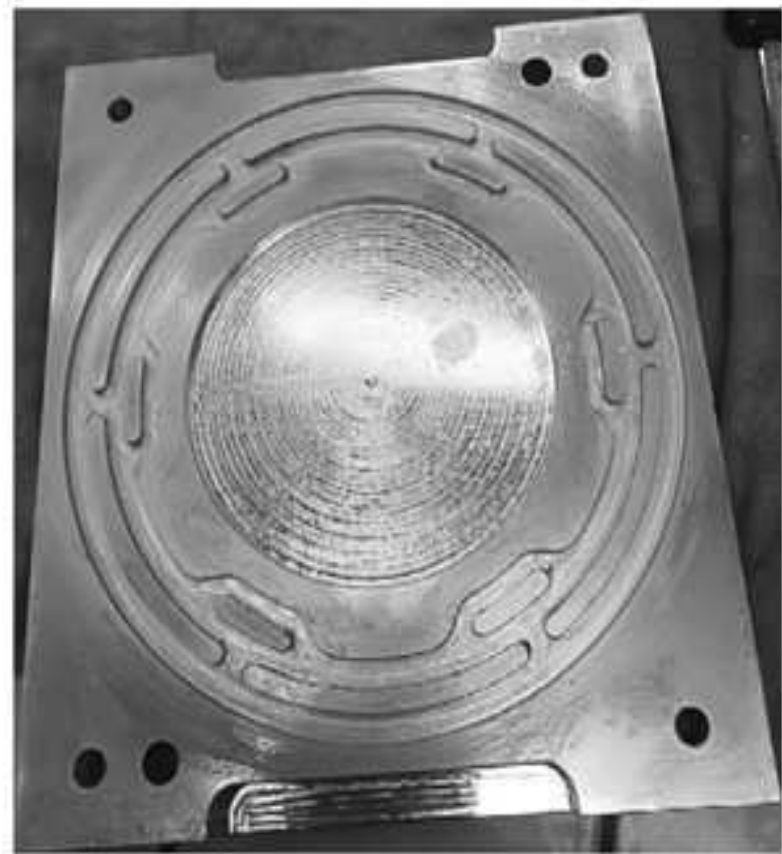

Fig. 11 Mold for the composite ring

These results indicate that the metal can be changed by composite material and the connecting components can be improved. The research also further indicates, there is an important balance between weight, stiffness, and appearance. Results describe that the final design of external fixator has the average weight and the average calculated stress during the loading. This means that all of three version are very similar. All of 3 versions in term of maximum loading meet the material requirements of carbon fiber composite with tensile strength $2550 \mathrm{MPa}$.

However, the visage and function of fixator in comparison with the 1st and 2nd version (an application of grooves) is much better in the 3 rd version and thus this construction will be further chosen for manufacturing and implementation into the testing process. As we can see in Fig. 10 and Fig. 11, after this selection, the mold and prepreg material has already been manufactured.

Nevertheless, more accurate details about the stiffness and loading of final external fixator can be measured after the stress test applied to the real product. And that is also the suggestion for another research of this external fixator to undergo a real product by the mechanical test.

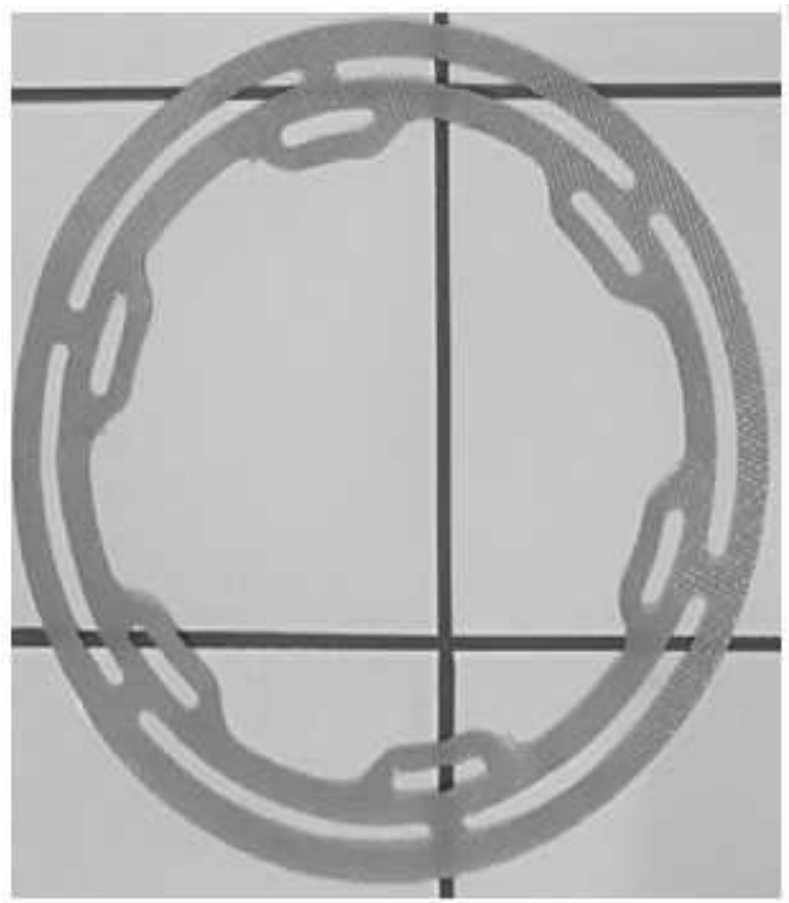

Fig. 12 Mould for the composite ring

\section{Acknowledgment}

This work and the project are realized with the financial support of the internal grant of TBU in Zlin No. IGA/FT/2019/001 funded from the resources of specific university research. 


\section{References}

[1] WENDLANDT R., SEIDE K., SCHULZ A.P., MUELLER N., JÜRGENS C. (2010). A robotic hexapod external fixator for the correction of angular deformity of long bones, Injury Extra. In: Sample Journal, Volume 41, Issue 12, 2010, pp. 142-143, ISSN 1572-3461, https://doi.org/10.1016/j.injury.2010.07.441.

[2] GESSMAN J., JETTKANT B., SCHILDHAUER T.A., SEYBOLD D. (2011) Mechanical stress on tensioned wires at direct and indirect loading: A biomechanical study on the Ilizarov external fixator, Injury, In: Sample Journal, Volume 42, Issue 10 1107-1111.

[3] SEDLÁK J., CHARVÁT O., MADAJ M. (2011) Technology of processing CT data of the Knee Joint, In: Sample Journal, Volume 10, ISSN 12132489, Brno University of Technology.

[4] JEVREMOVIC, D. P., PUŠKAR, M. BUDAK, I., VUKELIC, D., KOJIC, V., EGGBEER, D., WILLIAMS, R.J. An RE/RM approach to the design and manufacture of removable partial dentures with a biocompatibility analysis of the $\mathrm{F} 75 \mathrm{Co}$ Cr SLM alloy. Material and Technology, 2012.

[5] FOJTL, L., RUSNAKOVA, S., ZALUDEK, M., CAPKA, A., MANAS, L. Manufacturing and Mechanical Characterization of Bio-Based Laminates and Sandwich Structures", Materials Science Forum, Vol. 891, pp. 542-546, 2017

[6] M. B. STERniCK, D. DAllacosta, D. A. BENTO, M. L. REIS. Relationship between rigi- dity of external fixator and number of pins: Computer analysis using finite elements. Revista Brasilia de Ortopedia, Vol.: 47 (2012) 646 - 650.

[7] Migliaresi, C., NICOLI, F., ROSSI, S., PEGORETTI, A. Novel uses of carbon composites for the fabrication of external fixators, Mat. Sci. and Technol., 64 (2004) 1, 873-883.

[8] MEHBOOB, H., CHANG, N. Application of composites to orthopedic prostheses for effective bone healing, Composite Structures, 118 (2014) 1, 328341.

[9] RAMARAKRISHNA, S., MAYER, J., WINTERMANTEL, E., LEONG, K.W. Biomedical applications of polymer-composite materials: a review. Compos Sci Technol 2001;61(9):1189224.

[10] SUBA, O., SYKOROVA, L., LUKOVICS, I., Stress analysis of injection - molded cylindrical parts reinforced with short fibers. Manufacturing Technology [online]. 2012, vol. 12, iss. 13, s. 251254. [cit. 2017-05-12]. ISSN 1213-2489.

[11] RUSNAKOVA, S., ZALUDEK, M., BAKOSOVA, D. Processing engineering of large composites structures using low-pressure vacuum infusion. Manufacturing Technology [online]. 2012, vol. 12, iss. 12 , s. 83-86. [cit. 2017-05-12]. ISSN 1213-2489.

[12] ZHANG, H., XUE, F., XIAO, H.J. Ilizarov method in combination with autologous mesenchymal stem cells from iliac crest shows improved outcome in tibial non-union, Saudi Journal of Biological Sciences, (2016), ISSN 1319-562. 